\title{
Identification of Two Novel Amalgaviruses in the Common Eelgrass (Zostera marina) and in Silico Analysis of the Amalgavirus +1 Programmed Ribosomal Frameshifting Sites
}

\author{
Dongbin Park, Chul Jun Goh, Hyein Kim, and Yoonsoo Hahn* \\ Department of Life Science, Chung-Ang University, Seoul 06974, Korea \\ (Received on November 20, 2017; Revised on January 18, 2018; Accepted on January 18, 2018)
}

The genome sequences of two novel monopartite RNA viruses were identified in a common eelgrass (Zostera marina) transcriptome dataset. Sequence comparison and phylogenetic analyses revealed that these two novel viruses belong to the genus Amalgavirus in the family Amalgaviridae. They were named Zostera marina amalgavirus 1 (ZmAV1) and Zostera marina amalgavirus 2 (ZmAV2). Genomes of both ZmAV1 and ZmAV2 contain two overlapping open reading frames (ORFs). ORF1 encodes a putative replication factory matrixlike protein, while ORF2 encodes a RNA-dependent RNA polymerase (RdRp) domain. The fusion protein (ORF1+2) of ORF1 and ORF2, which mediates RNA replication, was produced using the +1 programmed ribosomal frameshifting (PRF) mechanism. The +1 PRF motif sequence, UUU_CGN, which is highly conserved among known amalgaviruses, was also found in ZmAV1 and ZmAV2. Multiple sequence alignment of the ORF1+2 fusion proteins from 24 amalgaviruses revealed that +1 PRF occurred only at three different positions within the 13-amino acid-long segment, which was surrounded by highly conserved regions on both sides. This suggested that the +1 PRF may be constrained by the structure of fusion proteins. Genome sequences of $\mathrm{ZmAV1}$ and $\mathrm{ZmAV}$, which are the first viruses to be identified in common eelgrass, will serve as useful resources for studying evolution and diversity

\footnotetext{
*Corresponding author.

Phone) +82-2-820-5812, FAX) +82-2-825-5206

E-mail)hahny@cau.ac.kr

(c) This is an Open Access article distributed under the terms of the Creative Commons Attribution Non-Commercial License (http:// creativecommons.org/licenses/by-nc/4.0) which permits unrestricted noncommercial use, distribution, and reproduction in any medium, provided the original work is properly cited.
}

Articles can be freely viewed online at www.ppjonline.org. of amalgaviruses.

Keywords : Amalgavirus, common eelgrass, +1 programmed ribosomal frameshifting

Handling Associate Editor : Lim, Hyoun-Sub

Common eelgrass (Zostera marina) is a marine monocotyledonous angiosperm that belongs to the family Zosteraceae (Lee et al., 2016). It is one of the most common seagrasses and is predominantly found in temperate coastal waters of the northern and southern hemispheres. Common eelgrasses play important roles in the coastal ecosystem. They form a physical habitat for many marine organisms and act as carbon sinks for long-term carbon storage (Dahl et al., 2016; Reynolds et al., 2016). Seagrasses are believed to have returned to sea at least three times from a terrestrial ancestor (Les et al., 1997). Therefore, they are valuable resources for understanding the mechanisms involved in adapting from a terrestrial to a marine habitat. Several studies using next-generation sequencing for transcriptomic analysis have been performed to investigate the genetic basis of this adaptation, including the role of abiotic stresses such as variable or limited light conditions and salinity tolerance (Kong et al., 2013, 2014; Wissler et al., 2009, 2011).

When total RNA from plant samples was extracted for transcriptomic analysis, viral genome RNAs were isolated together with the host RNAs. As a result, many plant RNAseq datasets contain associated RNA virus sequences, which can be identified by comprehensive bioinformatic analysis (Kim et al., 2014; Liu et al., 2012; Park and Hahn, 2017a, 2017b). In this study, two novel amalgaviruses were identified in a transcriptome dataset obtained for the common eelgrass (Kong et al., 2014). 
Transcriptome dataset of young leaves of common eelgrass (Kong et al., 2014) was downloaded from the Sequence Read Archive (SRA) of the National Center for Biotechnology Information (NCBI). The transcriptome data is available under the accession number SRA128272 and contains 11.1 gigabases of paired-end RNA-seq reads. Raw sequence data were screened using the sickle program (version 1.33; https://github.com/najoshi/sickle; parameters, -q $30-150$ ) to collect high-quality reads. De novo sequence assembly was performed using the SPAdes Genome Assembler (version 3.10.0; http://spades.bioinf. spbau.ru) (Bankevich et al., 2012).

To identify the virus-associated contigs in the assembled transcriptome contigs, a local BLASTX search was performed against a custom-built viral RNA-dependent RNA polymerase (RdRp) sequence database, using the following parameters: -evalue 1e-5 -max_target_seqs 1 . The representative RdRp database of known RNA viruses was constructed using sequences obtained from the Pfam database (release 30.0; http://pfam.xfam.org). The core viral RdRp motif sequences were collected from 19 Pfam families having the following accession numbers: PF00602, PF00603, PF00604, PF00680, PF00946, PF00972, PF00978, PF00998, PF02123, PF03431, PF04196, PF04197, PF05788, PF05919, PF07925, PF08467, PF08716, PF08717, and PF12426. Finally, a total of 345 non-redundant viral RdRp motif sequences were converted to a BLAST-searchable database.

Two common eelgrass transcriptome contigs were identified that contained RdRp motifs similar to that present in Southern tomato virus (STV) (UniProt accession number, A8R3Y5; Pfam accession number, PF02123). The two contigs showed about $68 \%$ identity in their nucleotide sequences, thereby indicating that they were derived from related but distinct viruses. STV is a member of the genus Amalgavirus of the family Amalgaviridae (Sabanadzovic et al., 2009), which suggested that the two contigs were ge- nomes of amalgaviruses or related viruses.

BLAST searches in the NCBI protein database confirmed that both contigs are closely related to plant amalgaviruses, including STV, Blueberry latent virus (BLV), and Rhododendron virus A (RHV-A) (Martin et al., 2011; Sabanadzovic et al., 2009, 2010). Therefore, the two contigs were tentatively named Zostera marina amalgavirus 1 (ZmAV1) and Zostera marina amalgavirus 2 (ZmAV2). The viral genome sequences of ZmAV1 and ZmAV2 were 3383 and $3316 \mathrm{nt}$ in length, respectively, and their annotation information is available in the NCBI nucleotide database under the accession numbers KY783316 (ZmAV1) and KY783317 (ZmAV2) (Table 1).

The common eelgrass RNA-seq reads were mapped to the $\mathrm{ZmAV} 1$ and $\mathrm{ZmAV} 2$ genome contigs using BWA and the variants were identified using SAMtools/BCFtools (Li and Durbin, 2009). There were 13 and 34 polymorphic sites in ZmAV1 and ZmAV2 genome sequences, respectively (Supplementary Table 1, 2). Hence, each of genome contigs is a composite sequence derived from at least two closely related clones.

Amalgaviruses are double-stranded RNA viruses with a single genomic RNA segment and infect various plants (Liu and Chen, 2009; Martin et al., 2011; Sabanadzovic et al., 2009, 2010). Their genomes contain two partially overlapping open reading frames (ORFs), a 5'-proximal ORF (ORF1) that encodes a putative replication factory matrixlike protein and the second ORF (ORF2) that encodes a RdRp motif. ORF1+2, formed by the fusion of ORF1 and ORF2 proteins, is expressed using a +1 programmed ribosomal frameshift (PRF) mechanism (Depierreux et al., 2016; Nibert et al., 2016).

Amalgaviruses share similarities in their genomic organization with the members of family Totiviridae, which infect fungi and protozoa, and are also phylogenetically related to viruses of the family Partitiviridae having several hosts, including plants, fungi, and apicomplexans (Martin

Table 1. Summary of amalgaviruses identified in this study

\begin{tabular}{|c|c|c|c|c|c|c|}
\hline Acronym & Full name & Accession & Length (nt) & ORF & Position & $\begin{array}{l}\text { Length } \\
\text { (aa) }\end{array}$ \\
\hline \multirow[t]{2}{*}{ ZmAV1 } & $\begin{array}{l}\text { Zostera marina } \\
\text { amalgavirus } 1\end{array}$ & KY783316 & 3383 & $\begin{array}{l}\text { Fusion protein (RNA-dependent RNA } \\
\text { polymerase) }\end{array}$ & $149-940,942-3299$ & 1049 \\
\hline & & & & $\begin{array}{l}\text { Putative replication factory matrix-like } \\
\text { protein }\end{array}$ & $149-1279$ & 382 \\
\hline \multirow[t]{2}{*}{ ZmAV2 } & $\begin{array}{l}\text { Zostera marina } \\
\text { amalgavirus } 2\end{array}$ & KY783317 & 3316 & $\begin{array}{l}\text { Fusion protein (RNA-dependent RNA } \\
\text { polymerase) }\end{array}$ & $111-941,943-3300$ & 1062 \\
\hline & & & & $\begin{array}{l}\text { Putative replication factory matrix-like } \\
\text { protein }\end{array}$ & $111-1298$ & 395 \\
\hline
\end{tabular}


et al., 2011). Therefore, it has been proposed that amalgaviruses possibly represent a transitional intermediate between totiviruses and partitiviruses (Krupovic et al., 2015).

Similar to other amalgaviruses, two overlapping ORFs were predicted in the genome sequences of ZmAV1 and ZmAV2. The proximal ORFs (ORF1) of ZmAV1 and ZmAV2 encoded 382 and 395 amino acid (aa) long proteins, respectively. ORF1 proteins showed sequence and structural similarities to ORF1 proteins of other amalgaviruses. ZmAV1 and ZmAV2 ORF1 proteins were predicted to be exclusively comprised of $\alpha$-helices and random coils, as observed in the other amalgaviruses (Krupovic et al., 2015).

The second protein encoded by amalgaviruses is an ORF1+2 fusion protein that uses a +1 PRF mechanism for proper translation. A +1 PRF motif sequence, UUU_CGN (underline, codon boundary for ORF1; N, any nucleotide; CGN, a rare arginine codon), is prevalent in plant amalgaviruses (Nibert et al., 2016; Park and Hahn, 2017b). The same +1 PRF motif was observed in other RNA viruses such as Zygosaccharomyces bailii virus $\mathrm{Z}(\mathrm{ZbV}-\mathrm{Z})$ and influenza $A$ viruses (Depierreux et al., 2016; Firth et al., 2012). The ZmAV1 and ZmAV2 genome sequences were predicted to have a putative +1 PRF sequence, UUU_CGU, which matched the consensus motif UUU_CGN (Fig. 1). The predicted ORF2 of ZmAV1 and ZmAV2 started at the nucleotide positions 942 and 943, respectively, which were the first bases after the +1 PRF site.

The ORF2-encoded peptides in ZmAV1 and ZmAV2 were 785 aa in length and had a conserved viral RdRp motif (Pfam accession number, PF02123). The ZmAV1 and ZmAV2 ORF1+2 fusion proteins produced by the +1 PRF mechanism were 1049 and 1062 aa in length, respectively, and were presumed to mediate viral replication.

The RdRp-motif-containing ORF2 protein sequences of ZmAV1 and ZmAV2 showed $45-50 \%$ aa sequence identity with those of the previously reported amalgaviruses (Table 2). The RdRp protein sequence identity threshold for assigning amalgaviruses to different species was 65 $70 \%$ (Nibert et al., 2016). This indicated that ZmAV1 and ZmAV2 are novel species of amalgaviruses. Furthermore, protein sequence identity between the ZmAV1 and ZmAV2 RdRps was $65.4 \%$, indicating that these two viruses could be considered different species. They showed about $25 \%$ aa sequence identity with the $R d R p$ protein of $\mathrm{ZbV}-\mathrm{Z}$, the type species of the fungus-infecting genus Zybavirus, which was the most closely related genus to the plant-infecting genus Amalgavirus belonging to the family Amalgaviridae (Depierreux et al., 2016).

The RdRp-motif containing ORF2 protein sequences of

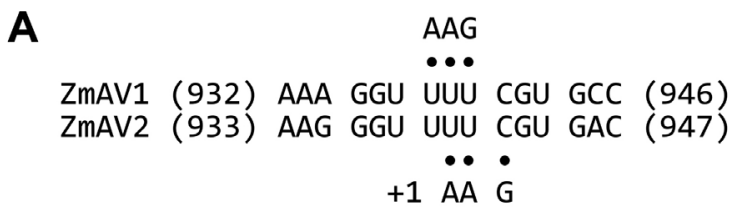

B

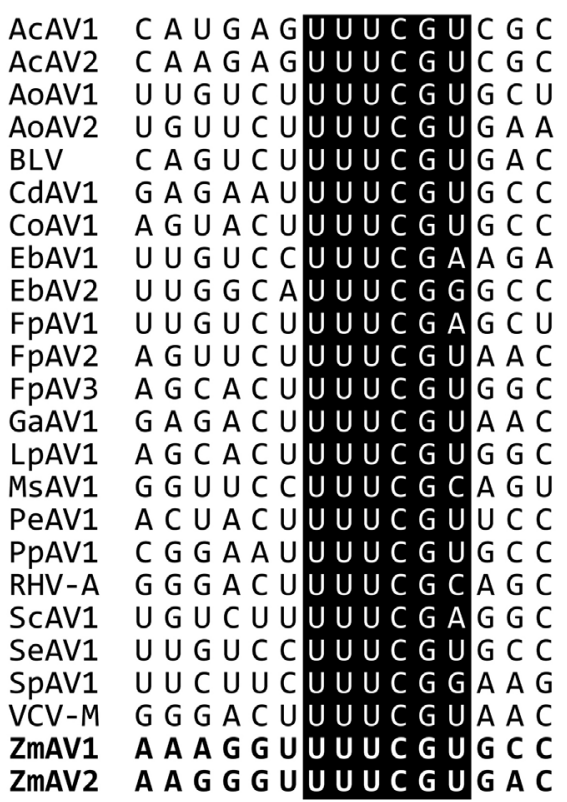

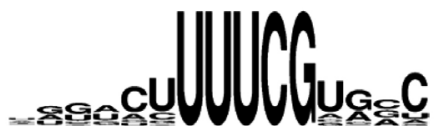

Fig. 1. (A) The predicted +1 programmed ribosomal frameshifting (PRF) motifs of ZmAV1 and ZmAV2. Both UUU and UUC codons can interact with the anticodon 3'-AAG-5' of the phenylalanyl-tRNA ( $\mathrm{tRNA}^{\text {Phe }}$ ). The $\mathrm{tRNA}^{\text {Phe }}$ positioned on UUU is thought to slip forward by one nucleotide, causing $a+1$ frameshift for continued translation. The codon-anticodon base pairs are marked using dots. (B) Sequence comparison of the +1 PRF motif of amalgaviruses. The ZmAV1 and ZmAV2 +1 PRF motif sequences are marked in boldface letters in the last two rows. Sequence logo representation at the bottom clearly shows the conserved UUU_CGN motif, with uracil (U) being slightly preferred over the other bases before the motif and at the position $\mathrm{N}$ of the motif.

ZmAV1, ZmAV2, and other amalgaviruses were multiply aligned using MUSCLE (https://www.drive5.com/muscle) (Edgar, 2004). Phylogenetic analysis by the neighborjoining method, using the MEGA7 software (http://www. megasoftware.net) (Kumar et al., 2016) confirmed that $\mathrm{ZmAV} 1$ and ZmAV2 are novel closely related species of amalgaviruses (Fig. 2). The observation that ZmAV1 and ZmAV2 formed a distinct clade among known amalgaviruses suggested that a single ancestral amalgavirus infected 
Table 2. Identities among the RdRp motif-containing ORF2 protein sequences of ZmAV1, ZmAV2, and related viruses

\begin{tabular}{|c|c|c|c|c|}
\hline Acronym & Full name & Accession number ${ }^{\mathrm{a}}$ & Identity with $\mathrm{ZmAV} 1^{\mathrm{b}}$ & Identity with $\mathrm{ZmAV}^{\mathrm{b}}$ \\
\hline BLV & Blueberry latent virus & NC_014593.1 & $369 / 744(50 \%)$ & $368 / 720(51 \%)$ \\
\hline FpAV2 & Festuca pratensis amalgavirus 2 & GBXXXZ1002308.1 & $357 / 722(49 \%)$ & $371 / 733(51 \%)$ \\
\hline FpAV3 & Festuca pratensis amalgavirus 3 & GBXZ01009138.1 & $381 / 743(51 \%)$ & $375 / 729(51 \%)$ \\
\hline LpAV1 & Lolium perenne amalgavirus 1 & GAYX01076418.1 & $367 / 717(51 \%)$ & $373 / 744(50 \%)$ \\
\hline AcAV1 & Allium cepa amalgavirus 1 & GAAO01011981.1 & $340 / 719(47 \%)$ & $344 / 733(47 \%)$ \\
\hline AcAV2 & Allium cepa amalgavirus 2 & GAAN01008476.1 & $362 / 769(47 \%)$ & $370 / 776(48 \%)$ \\
\hline PeAV1 & Phalaenopsis equestris amalgavirus 1 & GDHJ01028335.1 & $341 / 749(46 \%)$ & $343 / 727(47 \%)$ \\
\hline CaAV1 & Capsicum annuum amalgavirus 1 & JW101175.1 & $334 / 766(44 \%)$ & $334 / 759(44 \%)$ \\
\hline STV & Southern tomato virus & NC_011591.1 & $324 / 705(46 \%)$ & $326 / 737(44 \%)$ \\
\hline AoAV1 & Anthoxanthum odoratum amalgavirus 1 & GBIE01024896.1 & $327 / 731(45 \%)$ & $332 / 715(46 \%)$ \\
\hline FpAV1 & Festuca pratensis amalgavirus 1 & GBXZ01049574.1 & $315 / 716(44 \%)$ & $343 / 720(48 \%)$ \\
\hline RHV-A & Rhododendron virus A & NC_014481.1 & $345 / 717(48 \%)$ & $356 / 727(49 \%)$ \\
\hline MsAV1 & Medicago sativa amalgavirus 1 & GAFF01077243.1 & $318 / 723(44 \%)$ & $335 / 725(46 \%)$ \\
\hline VCV-M & Vicia cryptic virus $M$ & EU371896.1 & $329 / 715(46 \%)$ & $330 / 725(46 \%)$ \\
\hline CdAV1 & Cleome droserifolia amalgavirus 1 & GDRJ01026949.1 & $338 / 727(46 \%)$ & $347 / 729(48 \%)$ \\
\hline CoAV1 & Camellia oleifera amalgavirus 1 & GEFY01004381.1 & $358 / 759(47 \%)$ & $372 / 777(48 \%)$ \\
\hline GaAV1 & Gevuina avellana amalgavirus 1 & GEAC01063629.1 & $350 / 712(49 \%)$ & $372 / 769(48 \%)$ \\
\hline EbAV1 & Erigeron breviscapus amalgavirus 1 & GDQF01098448.1 & $358 / 732(49 \%)$ & $352 / 729(48 \%)$ \\
\hline EbAV2 & Erigeron breviscapus amalgavirus 2 & GDQF01120453.1 & $338 / 721(47 \%)$ & $360 / 741(49 \%)$ \\
\hline ScAV1 & Secale cereale amalgavirus 1 & GCJW01039808.1 & $331 / 716(46 \%)$ & $339 / 728(47 \%)$ \\
\hline SpAV1 & Spinach amalgavirus 1 & KY695011.1 & $356 / 722(49 \%)$ & $359 / 740(49 \%)$ \\
\hline PpAV1 & Pinus patula amalgavirus 1 & GECO01025317.1 & $329 / 719(46 \%)$ & $335 / 746(45 \%)$ \\
\hline $\mathrm{ZbV}-\mathrm{Z}$ & Zygosaccharomyces bailii virus $\mathrm{Z}$ & KU200450.1 & $127 / 512(25 \%)$ & $118 / 516(23 \%)$ \\
\hline
\end{tabular}

${ }^{a}$ Accession numbers of viral genome sequences.

${ }^{\mathrm{b}}$ Amino acid sequence identities have been described in the following format: identical residues/aligned length (\% identity).

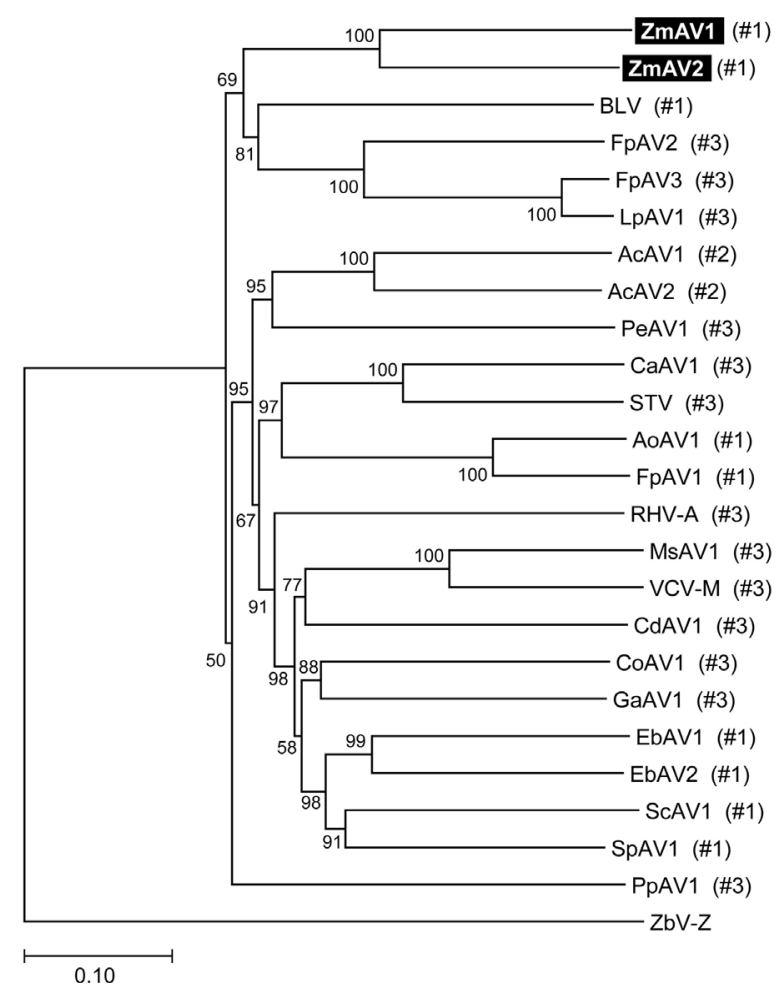

the common eelgrass in the past and subsequently diverged into two species during the course of evolution. However, it is also possible that two closely related amalgaviruses became independently associated with the common eelgrass.

To analyze whether the +1 PRF site in the fusion protein was conserved, multiple sequence alignment of the ORF1+2 fusion protein sequences of ZmAV1, ZmAV2, and 22 other amalgaviruses was performed (Supplementary Fig. 1). Interestingly, the +1 PRF site of 24 amalgaviruses occurred only at three different positions, which were designated as positions \#1, \#2, and \#3. The +1 PRF occurred at position $\# 1$ in 9 amalgaviruses, at position $\# 2$ in 2 , and at position \#3 in 13 (Fig. 3A). Two amalgaviruses, namely STV and Capsicum annuum amalgavirus 1 (CaAV1), had

Fig. 2. Phylogenetic tree of ZmAV1, ZmAV2, and related plant amalgaviruses. Multiple sequence alignment of the RdRp-motif containing ORF2 protein sequences was performed for inference of the phylogenetic tree. The fungus-infecting virus $\mathrm{ZbV}-\mathrm{Z}$ was used as an outgroup. The bootstrap values calculated from 100 replicates are shown at the nodes. The +1 PRF site position labels used in Fig. 3A are marked in parentheses. 
a +1 PRF motif different from those of the other amalgaviruses (Nibert et al., 2016). However, their +1 PRF motif occurred at the same position (position \#3) as in the other 11 amalgaviruses.

The consensus +1 PRF motif sequence is UUU_CGN, where underline indicates codon boundary for ORF1. Therefore, the last aa residue of ORF1 part of ORF1+2 fusion protein is always a phenylalanine (a UUU codon), except in STV and CaAV1, which have a leucine residue (a CUU codon) at this position because the +1 PRF sequence of these viruses is CUU_AGN (Nibert et al., 2016). When $\mathrm{a}+1$ PRF occurs, the codon boundary changes from UUU CGN (ORF1) to U_UUC_GNN (ORF2). The first aa residue of ORF2 encoded by a GNN codon can be one of valine, alanine, aspartic acid, glutamic acid, or glycine. All of these aa residues were observed in the 24 fusion proteins
A

Zmav

ZIMAV2

AOAV1

FpAV1

EBAV1

EbAV2

ScAV1

SpAV1

ACAV1

ACAV2

FpAV2

FpAV3

LpAV1

PeAV1

RHV-A

MsAV1

VCV-M

CdAv1

CoAV1

GaAV1

PpAV1

CaAv1

STV
\#1

(9)
\#2

(2)
\#3

(13)

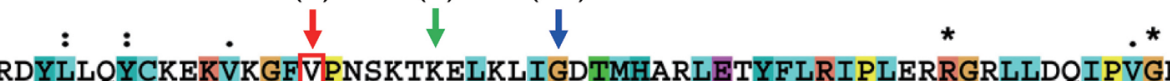
作 QADLTRYAREKIQSFVTOETREESPVLEIS IRQQLEORLISLPLELRKFHMKOVPFGIPLHK LTALREYVNKKILSFVLVENTGSRPALDTSWLPWTAKLLEKYPLPERISATAMI PMGRTTSP LHRLREYVGKKILSF ELVESGRYPIDLSTSWLPWTASLLMKYPLSERVSATIMI PMGTITFP AVKLFEYAKRKILSFEEMVTSNRKPIGKFTWMPRVETYLLSRPVKLRKRICSMCPVGLPPPP RTLLLEYCKKKILAF GPIRISDKPHPSRVCWLEQVETWLLSRPVALRREICSLVPVGFPHLP QDALMKYLAEQVCLFEATQTTPRPEMENTTWLSLVESRALSWPLPQRKSVLGIVPLGRPPLP QDIMERFMKERF LFF GRPPMNLGSAQQECSWLALVERKLWKMPLQRRLRLTGMIPIGILQAP QIPLKVWADSKLKELADNHEFVASARP SESWVSRVESHLHRLPLPQRVFQANNVPVGPVSQL QRLLQTWAASKIQDLRTNQEFVASQSSNDSWLSQVETHLWRLPLPLRLKWANTI PVGKVVSR TDALIEFGKQKILRCQEAGSGKLESS FVTYSLSSIQRMLLRYPLAQRKQMMEWI PMGVVPTR KNAMLNYGKLKIKKLEESKSKRELSTFVASSQSLIHRVLMSRPLKQRKELMAAI PMGVPTLP KNAMLNYGKLKIKKLAEGKSKRELSTFVASSQSLIHRVLMSHPLKQRKEMMAAI PMGVPLLP RNNLKHWIEEKILELDTVGEARRATTFVPTWQQRVERWLMKFELKLRLELLQQVVLGVPCAE QVALRKFADERI HFLDGIGEPKKAGTFA A SWQSSVLNLLLRQPLIRRREMMRMI PVGKVMLP SDFVRDYYNQKIVHLERSGEKKQAGS FA VSWWPLMEKWLLMFPLSTRSTLMEKIPVGKVHKP AEF IRDYYNQKVLHLDRS GEKKQAGTFVTSWWPDVEKWLLMLPLSQRLSLMEKI PVGKVPSP RDTLSEYLQRLVGLKAGQGRRREVENFVPSWQEWVSQLLMRYPLERRRWLLNRLVVGRINPP QQQLMQFLRGKILELDQIHERKQASTFVPYWLQSVVRRLHSRPLQRRLEMMEMI PVGKPNKP RPLMFEYLRKKILQFDAAADTKQAETFVTTWQQLVAQALMRHPLVERQKLANLVPVGRPPLP REALQNYCMRK IKHFEQESNEKQARNFVP SWMQLVSQRLWRLPLSTREREARGIPVGVVRLP VPLLQEYINQKIAHFDAVGDKRQVRHIVFNWQEWVMKWMVKWDVQTRVKLMRDIPVGTLNPR KDELQAF INAKI LGYEQLGDKGKSRYL GVSWQQWVLRWIMKWNQRTRKRLLKNLPVGKLRRG

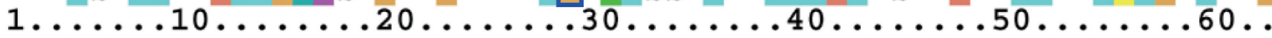

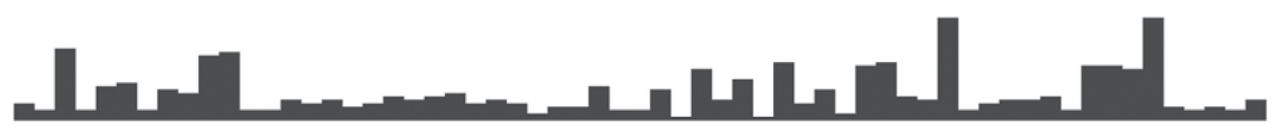

B
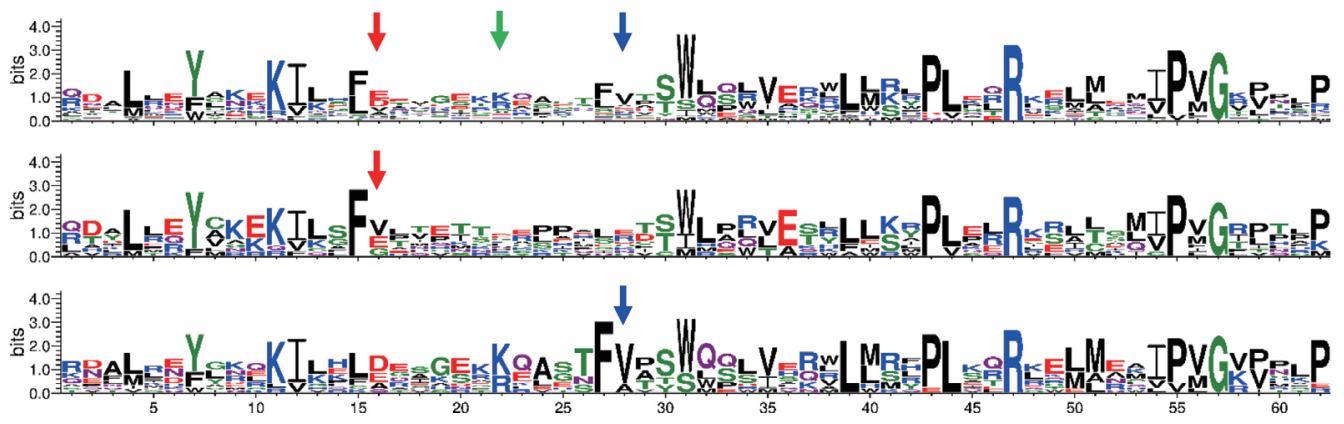

Fig. 3. (A) The +1 PRF sites and surrounding regions. Multiple sequence alignment of regions encompassing the +1 PRF sites was performed using the 24 full-length amalgavirus ORF1+2 fusion protein sequences (Supplementary Fig. 1). The +1 PRF occurred at three positions which were labelled as \#1,\#2, and \#3 and marked using red, green, and blue arrows, respectively. Number of viruses are shown in the parenthesis. The first aa residues of ORF2 are shown in colored boxes. (B) Sequence logo representations generated from all viruses (top), and those generated from viruses with the +1 PRF sites at position \#1 (middle) and position \#3 (bottom). Notably, the +1 PRF sites are embedded in a segment with diverse aa residues and surrounded by conserved regions. 
(Fig. 3A), suggesting that any aa of them was acceptable at this position. The most frequent base present at the second base position of the GNN codon was uracil (U) (Fig. 1B). Because a GUN codon codes for a valine, the most common residue of the first aa of ORF2 is valine.

The three +1 PRF sites were located within a 13-aa-long segment, which contained diverse residues and was surrounded by many conserved residues (Fig. 3B). Interestingly, the three positions were evenly spaced. There were five residues present between positions \#1 and \#2 and between \#2 and \#3. Phylogenetic distribution of the +1 PRF sites revealed that the position shifting event occurred frequently during the evolution of amalgaviruses (Fig. 2). However, only the three specific positions closely located to each other were repeatedly involved. This observation strongly indicated that the +1 PRF site was highly constrained, probably by the folding of fusion proteins. Secondary structure prediction of selected fusion proteins using PSIPRED (version 3.3; http://bioinf.cs.ucl.ac.uk/psipred) (McGuffin et al., 2000) showed that the +1 PRF sites were preferentially located within a random coil segment between two $\alpha$-helices, one from ORF1 and the other from ORF2, or near the tip of an $\alpha$-helix. The +1 PRF site seems to be selected not to disrupt the proper folding of ORF1+2 fusion protein.

In conclusion, the full-length genome sequences of two novel amalgaviruses (ZmAV1 and ZmAV2) associated with common eelgrass were identified. Notably, no known viruses have been identified in eelgrasses (genus Zostera) (http://www.genome.jp/virushostdb; as of July 28, 2017) (Mihara et al., 2016). ZmAV1 and ZmAV2 are the first viruses to be identified in eelgrasses. Comparison of the ORF1+2 fusion proteins showed that three +1 PRF sites were preferred, potentially owing to structural constraints in fusion proteins.

\section{Acknowledgments}

This research was supported by the National Research Foundation of Korea funded by the Korea Government (grant number 2017R1A1B400586).

\section{References}

Bankevich, A., Nurk, S., Antipov, D., Gurevich, A. A., Dvorkin, M., Kulikov, A. S., Lesin, V. M., Nikolenko, S. I., Pham, S., Prjibelski, A. D., Pyshkin, A. V., Sirotkin, A. V., Vyahhi, N., Tesler, G., Alekseyev, M. A. and Pevzner, P. A. 2012. SPAdes: a new genome assembly algorithm and its applications to single-cell sequencing. J. Comput. Biol. 19:455-477.

Dahl, M., Deyanova, D., Gutschow, S., Asplund, M. E., Lyimo, L.
D., Karamfilov, V., Santos, R., Bjork, M. and Gullstrom, M. 2016. Sediment properties as important predictors of carbon storage in Zostera marina meadows: a comparison of four European areas. PLoS One 11:e0167493.

Depierreux, D., Vong, M. and Nibert, M. L. 2016. Nucleotide sequence of Zygosaccharomyces bailii virus Z: Evidence for +1 programmed ribosomal frameshifting and for assignment to family Amalgaviridae. Virus Res. 217:115-124.

Edgar, R. C. 2004. MUSCLE: multiple sequence alignment with high accuracy and high throughput. Nucleic Acids Res. 32:1792-1797.

Firth, A. E., Jagger, B. W., Wise, H. M., Nelson, C. C., Parsawar, K., Wills, N. M., Napthine, S., Taubenberger, J. K., Digard, P. and Atkins, J. F. 2012. Ribosomal frameshifting used in influenza A virus expression occurs within the sequence UCC UUU_CGU and is in the +1 direction. Open Biol. 2:120109.

Kim, D. S., Jung, J. Y., Wang, Y., Oh, H. J., Choi, D., Jeon, C. O. and Hahn, Y. 2014. Plant RNA virus sequences identified in kimchi by microbial metatranscriptome analysis. J. Microbiol. Biotechnol. 24:979-986.

Kong, F., Zhou, Y., Sun, P., Liu, L. and Mao, Y. 2013. Generation and analysis of expressed sequence tags fromthe salt-tolerant eelgrass species, Zostera marina. Acta Oceanologica Sinica 32:68-78.

Kong, F., Li, H., Sun, P., Zhou, Y. and Mao, Y. 2014. De novo assembly and characterization of the transcriptome of seagrass Zostera marina using Illumina paired-end sequencing. PLoS One 9:e112245.

Krupovic, M., Dolja, V. V. and Koonin, E. V. 2015. Plant viruses of the Amalgaviridae family evolved via recombination between viruses with double-stranded and negative-strand RNA genomes. Biol. Direct 10:12.

Kumar, S., Stecher, G. and Tamura, K. 2016. MEGA7: molecular evolutionary genetics analysis version 7.0 for bigger datasets. Mol. Biol. Evol. 33:1870-1874.

Lee, H., Golicz, A. A., Bayer, P. E., Jiao, Y., Tang, H., Paterson, A. H., Sablok, G., Krishnaraj, R. R., Chan, C. K., Batley, J., Kendrick, G. A., Larkum, A. W., Ralph, P. J. and Edwards, D. 2016. The genome of a southern hemisphere seagrass species (Zostera muelleri). Plant Physiol. 172:272-283.

Les, D. H., Cleland, M. A. and Waycott, M. 1997. Phylogenetic studies in alismatidae, II: Evolution of marine angiosperms (seagrasses) and hydrophily. Syst. Bot. 22:443-463.

Li, H. and Durbin, R. 2009. Fast and accurate short read alignment with Burrows-Wheeler transform. Bioinformatics 25:1754-1760.

Liu, H., Fu, Y., Xie, J., Cheng, J., Ghabrial, S. A., Li, G., Yi, X. and Jiang, D. 2012. Discovery of novel dsRNA viral sequences by in silico cloning and implications for viral diversity, host range and evolution. PLoS One 7:e42147.

Liu, W. and Chen, J. 2009. A double-stranded RNA as the genome of a potential virus infecting Vicia faba. Virus Genes 39:126-131.

Martin, R. R., Zhou, J. and Tzanetakis, I. E. 2011. Blueberry la- 
tent virus: an amalgam of the Partitiviridae and Totiviridae. Virus Res. 155:175-180.

McGuffin, L. J., Bryson, K. and Jones, D. T. 2000. The PSIPRED protein structure prediction server. Bioinformatics 16:404405.

Mihara, T., Nishimura, Y., Shimizu, Y., Nishiyama, H., Yoshikawa, G., Uehara, H., Hingamp, P., Goto, S. and Ogata, H. 2016. Linking virus genomes with host taxonomy. Viruses 8:66.

Nibert, M. L., Pyle, J. D. and Firth, A. E. 2016. A +1 ribosomal frameshifting motif prevalent among plant amalgaviruses. Virology 498:201-208.

Park, D. and Hahn, Y. 2017a. Genome sequence of Spinach cryptic virus 1 , a new member of the genus Alphapartitivirus (family Partitiviridae), identified in spinach. J. Microbiol. Biotechnol. 27:834-837.

Park, D. and Hahn, Y. 2017b. Genome sequences of Spinach deltapartitivirus 1, Spinach amalgavirus 1, and Spinach latent virus identified in spinach transcriptome. J. Microbiol. Biotechnol. 27:1324-1330.
Reynolds, L. K., DuBois, K., Abbott, J. M., Williams, S. L. and Stachowicz, J. J. 2016. Response of a habitat-forming marine plant to a simulated warming event is delayed, genotype specific, and varies with phenology. PLoS One 11:e154532.

Sabanadzovic, S., Abou Ghanem-Sabanadzovic, N. and Valverde, R. A. 2010. A novel monopartite dsRNA virus from rhododendron. Arch. Virol. 155:1859-1863.

Sabanadzovic, S., Valverde, R. A., Brown, J. K., Martin, R. R. and Tzanetakis, I. E. 2009. Southern tomato virus: The link between the families Totiviridae and Partitiviridae. Virus Res. 140:130-137.

Wissler, L., Codoner, F. M., Gu, J., Reusch, T. B., Olsen, J. L., Procaccini, G. and Bornberg-Bauer, E. 2011. Back to the sea twice: identifying candidate plant genes for molecular evolution to marine life. BMC Evol. Biol. 11:8.

Wissler, L., Dattolo, E., Moore, A. D., Reusch, T. B., Olsen, J. L., Migliaccio, M., Bornberg-Bauer, E. and Procaccini, G. 2009. Dr. Zompo: an online data repository for Zostera marina and Posidonia oceanica ESTs. Database (Oxford) 2009:bap009. 